\title{
THE ESTIMATION OF STRUCTURAL MODAL PARAMETERS FROM THE RESPONSES OF THE GISBORNE POST OFFICE BUILDING IN RECENT EARTHQUAKES
}

\author{
J.X. Zhao ${ }^{1}$
}

\begin{abstract}
SUMMARY
Two complete sets of records obtained from a strong-motion accelerograph array in the Gisborne Post Office building during earthquakes of 1982 and 1993 were analyzed by using systems identification techniques to estimate the modal parameters. Nonlinear responses of the soil-structure system in both horizontal and vertical directions were indicated by significant decreases in the estimated first mode frequencies for moderate to strong ground motion in 1993 compared to those for the small amplitude ground motion in 1982. The analysis of second floor and remote site records from a 1985 earthquake indicated that nonlinear responses also occurred then. Soil-structure interaction was found to be significant for both vertical and horizontal responses. Using a numerical model of the foundation-soil system, the foundation rocking frequency and first fixed-base modal frequency were estimated. It was found that frequencies of the building's first fixed-base mode, foundation translation and rocking all were reduced in the 1993 earthquake compared with those of the 1982 earthquake, indicating that nonlinear responses occurred in both the building and the soil in the 1993 earthquake. Possible evidence for a cutoff frequency at the soil site was also identified. Because of soil-structure interaction, the fixed-base horizontal response in the N44E direction was reduced by possibly $40-50 \%$ in the 1982 earthquake, and about $30 \%$ in the 1993 event, compared with the recorded first modal response of the soil-structure system.
\end{abstract}

\section{INTRODUCTION}

The Gisborne Post Office is a 6-storey reinforced concrete moment-resisting frame building with a $0.38 \mathrm{~m}$ thick reinforced concrete mat foundation in the basement. The building has two bays in the N44E direction $(16.5 \mathrm{~m})$ and 10 bays in the S46E direction $(50.2 \mathrm{~m})$ and the building height above the mat foundation is $25.5 \mathrm{~m}$. The embedment depth of the foundation is about $2.4 \mathrm{~m}$. The building is located on a soft soil site with about $40 \mathrm{~m}$ of recent marine and fluvial sediments above a siltstone base $[1,2]$. The shear wave velocity of the ground surface soil is $98 \mathrm{~m} / \mathrm{s}$ and gradually increases to $240 \mathrm{~m} / \mathrm{s}$ at the depth of $24 \mathrm{~m}$ [3].

Mechanical-optical strong motion accelerographs were installed at a free-field site in the carpark and on the ground floor, the second floor and the top floor when the building was constructed in 1976 . The instruments were inter-connected and the timing marks for records were generated by the instrument on the ground floor. The three instruments inside the building are almost in the centre of the building. The carpark (free-field) site is about $20 \mathrm{~m}$ away from the building.

Two complete sets of earthquake records were obtained in 1982 and 1993. The 1982 earthquake had a local magnitude of 5.1 and an assigned depth of $33 \mathrm{~km}$. The epicentral distance to the Gisborne Post Office was $25 \mathrm{~km}$. A horizontal peak ground acceleration (PGA) of $0.06 \mathrm{~g}$ was recorded at the carpark site and a horizontal peak acceleration of $0.09 \mathrm{~g}$ was recorded on the top floor of the building [1]. Vertical peak accelerations of $0.019 \mathrm{~g}$ and $0.023 \mathrm{~g}$ were recorded at the carpark and top floor sites respectively. Intensities of MM V were reported in Gisborne. The building responded essentially elastically in the earthquake because of the small amplitudes of the ground shaking. The 1993 (Ormond) earthquake was centred at an epicentral distance of 23 $\mathrm{km}$ from Gisborne Post Office and had moment magnitude of 6.2 and a focal depth of $48 \mathrm{~km}$. A horizontal PGA of $0.26 \mathrm{~g}$ was recorded at the carpark site and a peak acceleration of $0.25 \mathrm{~g}$ was recorded on the top floor [4]. Vertical peak accelerations of $0.08 \mathrm{~g}$ and $0.18 \mathrm{~g}$ were recorded at the carpark and the top floor sites. Intensities MM V and MM VI were reported in Gisborne [5]. The building showed some light damage, such as cracks in the walls and ceilings. Analysis of the 1993 earthquake records indicated nonlinear response of the building, with a significant reduction (30\%) of the first mode frequency compared to that derived from the 1982 earthquake records.

Two additional records were also obtained from the carpark and second floor sites in an earthquake in 1985. The complete acceleration histories of the ground floor and the top floor were not recorded because of failure of the film transportation mechanism in the accelerographs, but peak acceleration values were obtained [1]. The 1985 earthquake was centred at an epicentral distance of $54 \mathrm{~km}$ from Gisborne at a focal depth of $41 \mathrm{~km}$ and had moment magnitude of 5.9. The PGA in the carpark was $0.095 \mathrm{~g}$ and the top

\footnotetext{
${ }^{1}$ Institute of Geological \& Nuclear Sciences, P.O. Box 30-368, Lower Hutt, New Zealand, (Member).
} 
floor response was $0.2 \mathrm{~g}$. Nonlinear response was also apparent from analysis of the carpark and the second floor records, with a $20 \%$ reduction of the first mode frequency compared with that derived from the 1982 earthquake records. Because the Fourier spectra of the ground records had dominant peaks at the building's first mode frequency, large amplification of the peak ground acceleration occurred within the structure.

TABLE I: $\quad$ Peak Accelerations (g)

\begin{tabular}{||l|l|l|l|l|l|l||}
\hline \hline Event & \multicolumn{2}{|c|}{1982} & \multicolumn{3}{c||}{1993} \\
\hline Direction & N44E & S46E & Vert. & N44E & S46E & Vert. \\
\hline Carpark & 0.06 & 0.06 & 0.019 & 0.26 & 0.18 & 0.081 \\
\hline Ground Fl. & 0.03 & 0.04 & 0.020 & 0.14 & 0.12 & 0.056 \\
\hline 2nd Fl. & 0.05 & 0.07 & 0.023 & 0.20 & 0.17 & 0.130 \\
\hline Top Fl. & 0.08 & 0.09 & 0.023 & 0.25 & 0.22 & 0.180 \\
\hline
\end{tabular}

TABLE II: Fundamental Modal Parameters Estimated from the 1982 Records (Time Window 0-14s, Frequency Band 0.4-6 Hz)

\begin{tabular}{||l|l|l|l|l|l|l||}
\hline \multicolumn{6}{||c|}{ Ground floor Input } & \multicolumn{5}{|c||}{ Free-field input } \\
\hline $\begin{array}{l}\bar{\omega}_{\mathrm{h}} / 2 \pi \\
(\mathrm{Hz})\end{array}$ & $\begin{array}{c}\bar{\xi}_{\mathrm{h}} \\
(\%)\end{array}$ & $\overline{\mathrm{L}}_{\mathrm{h}}$ & $\begin{array}{l}\omega_{\mathrm{N}} / 2 \pi \\
(\mathrm{Hz})\end{array}$ & $\begin{array}{l}\xi_{\mathrm{N}} \\
(\%)\end{array}$ & $\mathrm{L}_{\mathrm{N}}$ & $\mathrm{L}_{\mathrm{h}}$ \\
\hline \multicolumn{7}{|c||}{ N44E Direction } \\
\hline 1.35 & 3.66 & 1.21 & 1.28 & 6.38 & 1.12 & 0.047 \\
\hline Error J=0.08 & \multicolumn{7}{|c|}{$\mathrm{J}=0.36$} \\
\hline \multicolumn{7}{|c|}{$\mathrm{S} 46 \mathrm{E}$ Direction } \\
\hline 1.32 & 3.86 & 1.29 & 1.28 & 4.13 & 1.15 & 0.037 \\
\hline $\mathrm{J}=0.10$ & & $\mathrm{~J}=0.36$ \\
\hline
\end{tabular}

Note: Normalized error $\mathbf{J}$ denotes the mean square error between the measured and the modal accelerations over the identification frequency band normalized by the mean square acceleration response over the same frequency band [7].
The two complete sets of earthquake records from the Gisborne Post Office in 1982 and 1993 offer a good opportunity to study the building's response characteristics, and to estimate the dynamic parameters which are important to engineering design of similar types of buildings.

\section{MAJOR HORIZONTAL RESPONSE CHARACTERISTICS}

The frequency of the first dominant peak in the transfer function between the records from the top floor and the "free field" (carpark) sites is about $1.3 \mathrm{~Hz}$ for both directions in the 1982 earthquake and $0.9-1.0 \mathrm{~Hz}$ in the 1993 earthquake. Theory shows that the frequency of the first dominant peak for this choice of transfer function should be very close to the first mode frequency of the overall soil-structure system (Section 3.4.3 of Wolf [6]).

In both the 1982 and 1993 earthquakes, the acceleration response spectra of the carpark site records and the ground floor records have similar amplitudes at periods longer than the fundamental mode periods shown by the transfer functions $(0.8 \mathrm{~s}$ in the 1982 earthquake and $1.1 \mathrm{~s}$ in the 1993 earthquake), but the spectra of the ground floor records are much smaller than those of the carpark site records at shorter periods (Figure 1). The peak accelerations recorded at the ground floor site also were much smaller than those recorded at the carpark site (see Table 1). Both effects are indications of soil-structure interaction due to the soil flexibility at the site. The ground floor Fourier spectra of the N44E component were significantly lower than those of the carpark records at the building's modal frequencies, which indicates that inertial interaction, i.e., modal frequency shift and modal damping increase due to foundation soil flexibility, was a major factor in the response of the building. The ground floor Fourier spectra were reduced also at high frequencies indicating the significance of kinematic interaction, which will be investigated elsewhere.

The Fourier spectrum of the N44E component of the top floor record from the 1982 earthquake has a dominant peak at about $1.42 \mathrm{~Hz}$ while the dominant peak appears at $0.92 \mathrm{~Hz}$ in the top floor record from the 1993 earthquake (Figure 2a). A shift of the frequency of the peak also occurred in the S46E component (1.23 $\mathrm{Hz}$ to $1.04 \mathrm{~Hz}$, Figure 2b). The shift of the peak frequency is an indication of nonlinear response being developed in the 1993 earthquake.

The peak acceleration recorded on the top floor in the N44E direction in the 1993 earthquake was slightly smaller than that recorded at the carpark site, partially because the Fourier spectrum of the ground record has relatively low amplitudes at the building's modal frequencies compared with those at the other frequencies. For the same reason, the peak acceleration at the top floor in the S46E direction in 1993 was amplified by only about $20 \%$ with respect to the carpark site. If the ground motion had peaked at the building's modal frequencies, building resonance would have occurred and large amplification of the peak acceleration would have been observed, as happened in the 1985 earthquake. 


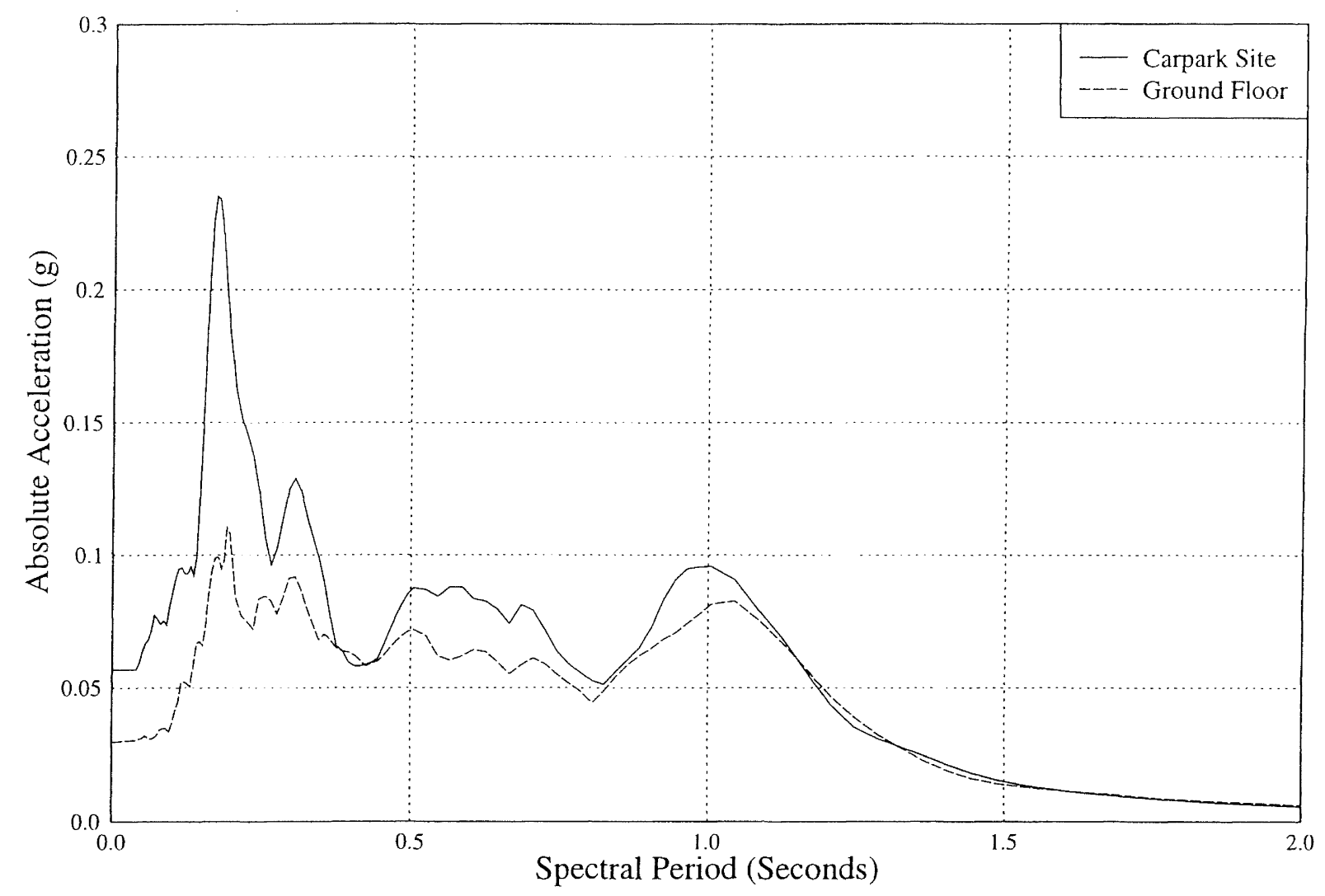

(a). 1982 Earthquake

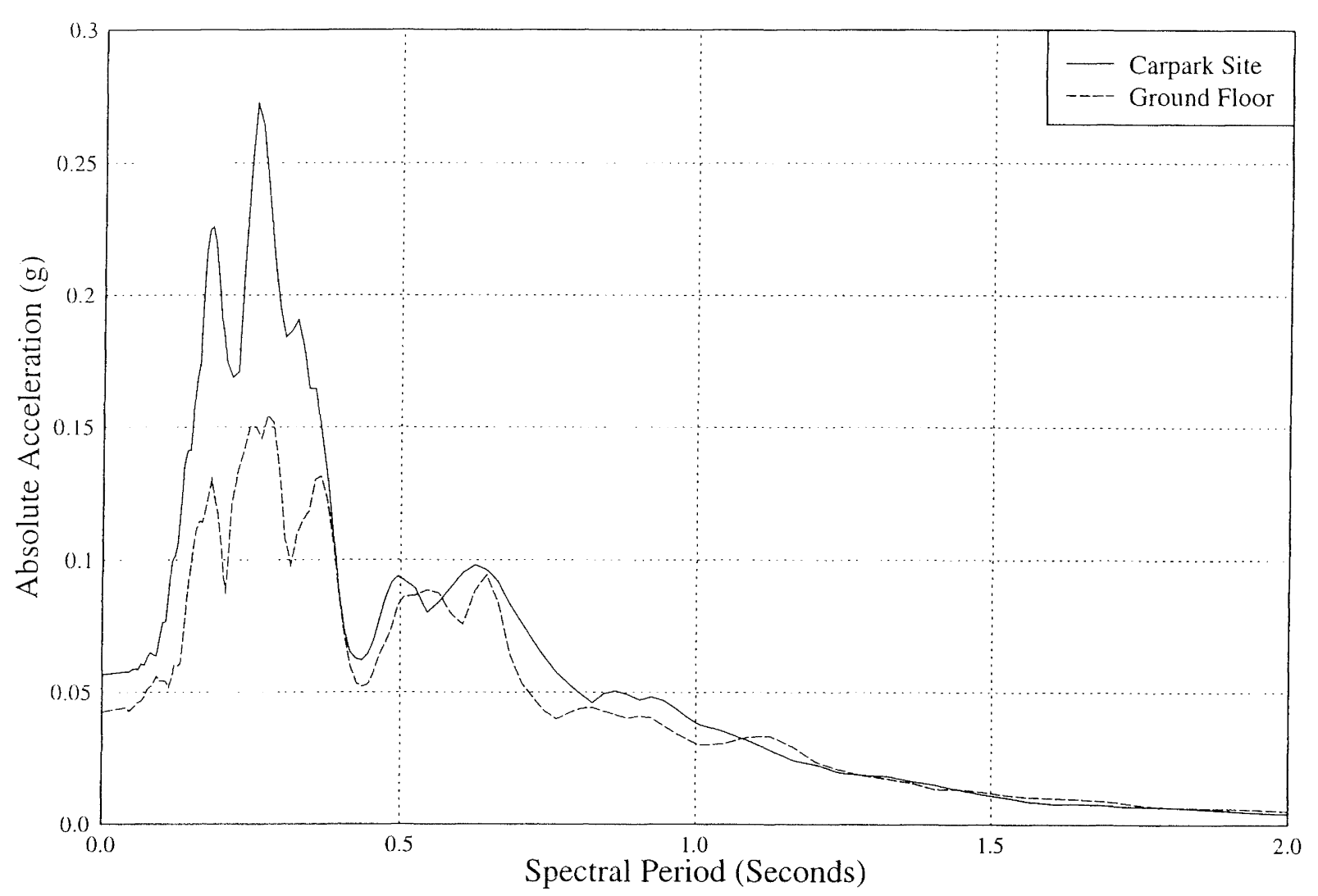

FIGURE 1

(b). 1993 Earthquake

Response spectra of carpark site and ground floor records in the N44E direction. Note that the ground floor spectra are smaller than those of the carpark site at short periods. 


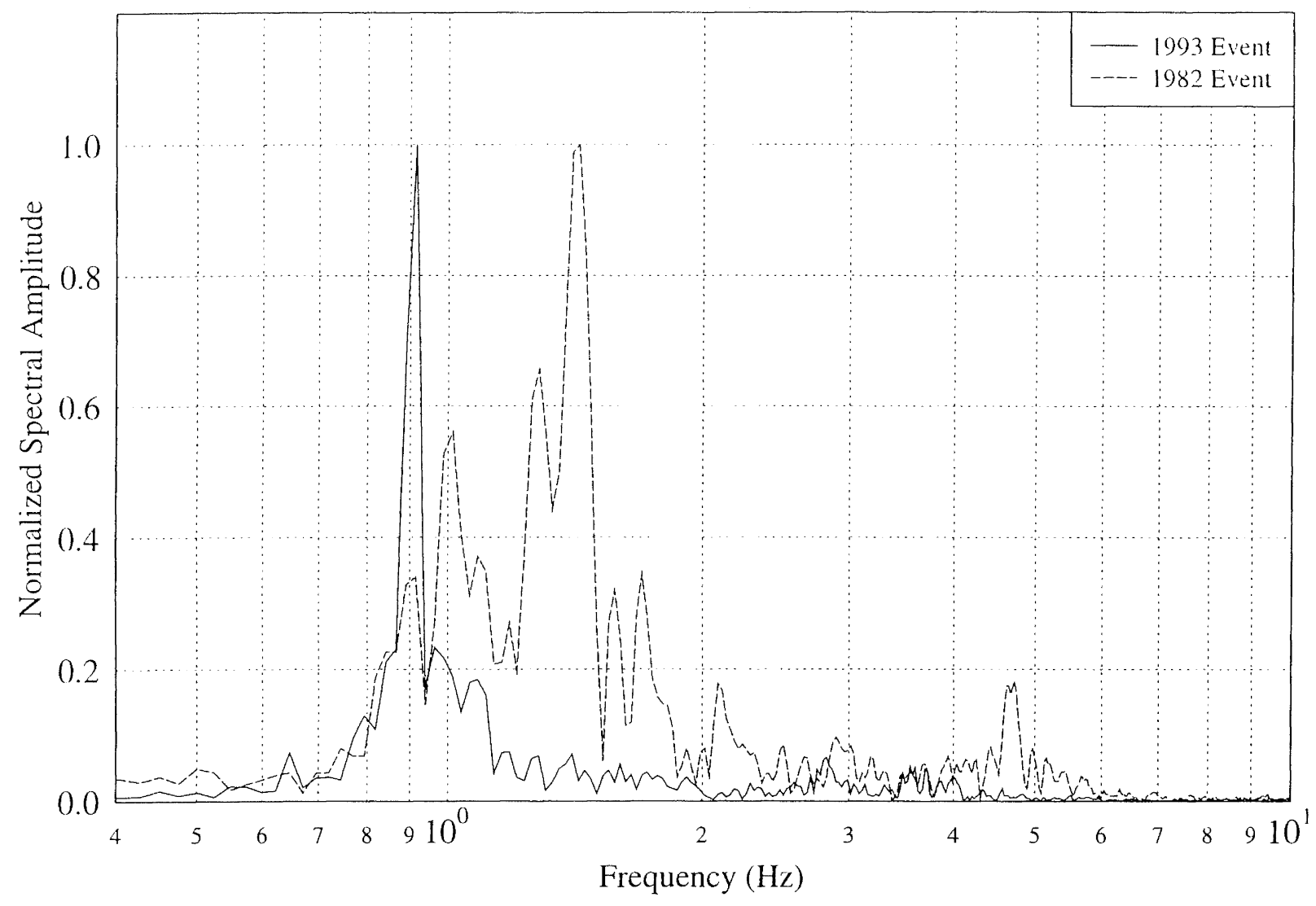

(a). N44E component

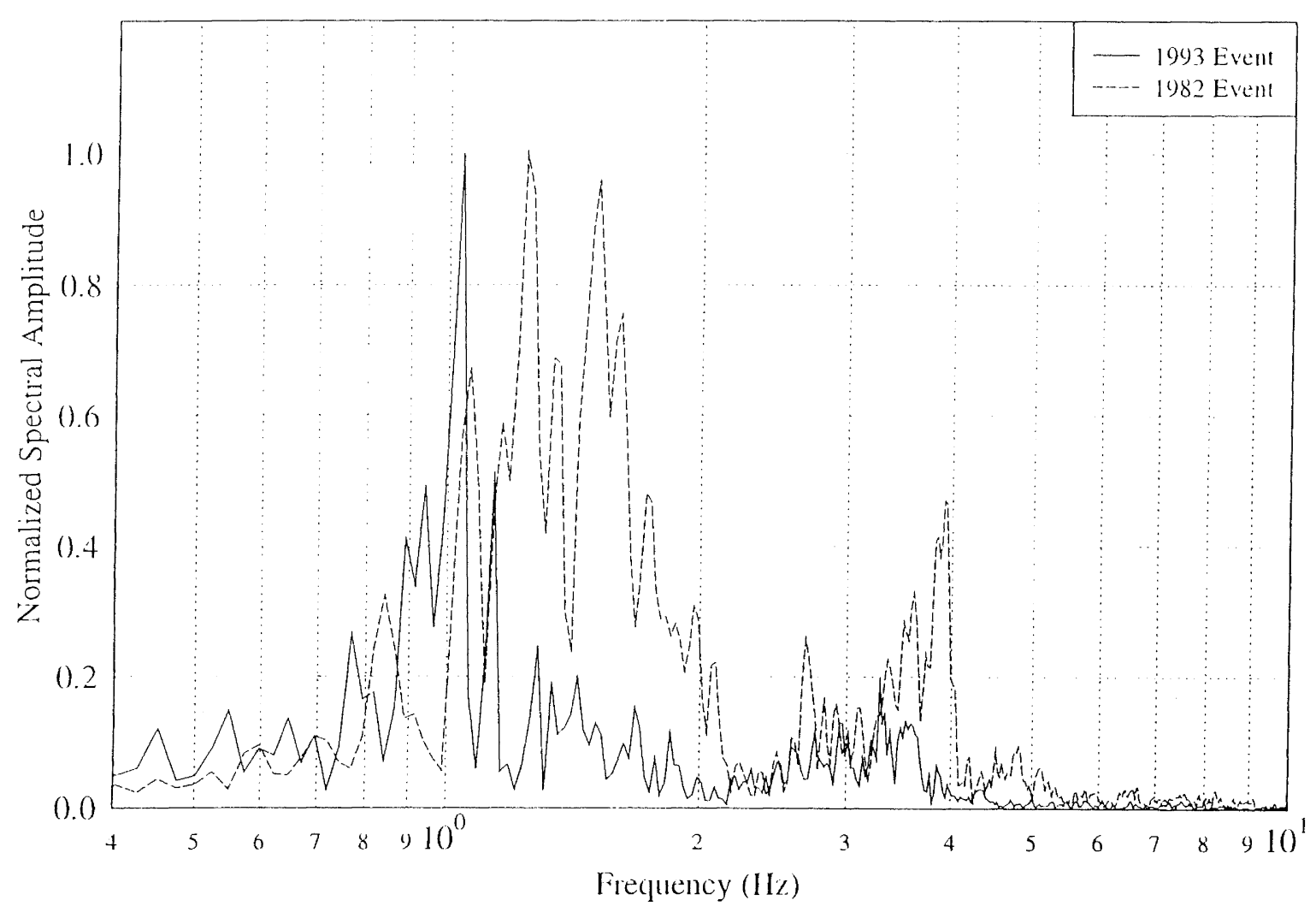

(b). S46E Component

FIGURE 2 Normalised Fourier spectra of top floor records. Note that the dominant peaks shift to low frequency in the 1993 event compared with those in the 1982 event. The relative strength of the second mode response in the 1993 event is lower than that in the 1982 event. 


\section{METHODS OF ANALYSIS}

A combination of transfer functions and a systems identification method $[7,8]$ were used to estimate modal parameters of the soilstructure system in the 1982 and 1993 earthquakes. The methods allow investigation of changes in these parameters between the small amplitude ground motions in 1982 and the stronger motions in 1993. In the systems identification method used here, the dynamic equilibrium equations of the building system are decomposed into independent modal response equations so that modal parameters can be estimated. In order to use the ground floor records and the carpark site records as excitation, the following assumptions are made.

The system is assumed to have classical mode shapes and independent responses in the N44E and S46E directions. Note that an assumption of classical damping is not valid because the radiation damping contributed from the foundation soil makes the soilstructure system damping non-classical [6]. However, the first mode response can be well approximated by using classical mode shapes [9].

(2) The coupling between the recorded vertical and horizontal responses is assumed to be negligible because the instruments are all near the centre of the building.

(3) For the ground floor records to be an accurate representation of base excitation it is necessary to assume that the basement of the building is rigid and that the influence of rocking motion on the ground floor records is small.

The carpark site record is assumed to represent the "free field" motion unmodified by the building response.

(5) The effect of frequency dependence of the foundation stiffness on the structural response is assumed to be negligible.

(6) Equivalent linear models can be used to estimate nonlinear response in a moderate earthquake.

For the $\mathrm{jth}$ mode displacement at position $\mathrm{i}, \mathrm{x}_{\mathrm{ij}}$, relative to excitation $\mathrm{z}_{\mathrm{g}}[7]$,

where $\omega_{\mathrm{j}}$ is the $\mathrm{jth}$ mode frequency, $\xi_{\mathrm{j}}$ is the $\mathrm{jth}$ mode damping

$\ddot{X}_{i j}+2 \xi_{j} \omega_{j} \dot{X}_{i j}+\omega_{j}^{2} x_{i j}=-L_{i j} \ddot{Z}_{g}$

ratio. The effective participation factor (EMPF) at position i for the $\mathrm{jth}$ mode $\mathrm{L}_{\mathrm{ij}}$ can be written as

where $\phi_{\mathrm{ij}}$ is the value of the jth mode shape at position $\mathrm{i},\{\phi\}_{\mathrm{j}}$ is

$\mathrm{L}_{\mathrm{ij}}=\phi_{\mathrm{ij}} \frac{\{\phi\}_{\mathrm{j}}^{\mathrm{T}}[\mathrm{M}]\{\mathbf{r}\}}{\{\phi\}_{\mathrm{j}}^{\mathrm{T}}[\mathrm{M}]\{\phi\}_{\mathrm{j}}}$

the jth mode shape, $[\mathrm{M}]$ is the mass matrix of the structure, and $\{\mathrm{r}\}$ is the pseudostatic influence vector.

The method used here is to select values of the modal parameters $\omega_{\mathrm{j}}, \xi_{\mathrm{j}}$ and $\mathrm{L}_{\mathrm{ij}}$ for a number of modes to achieve a frequencydomain least-squares match over a selected frequency band between the Fourier spectra of the measured acceleration response and the model response to the recorded excitation [7]
Transfer functions between the building's responses and the excitations were calculated to give initial estimates of the modal frequencies for the systems identification procedure. Modal parameters were estimated using the top floor and the second floor records as responses when using the ground floor records as excitations. The ground floor records were also used as responses when the carpark records were used as excitations. Using ground floor records as responses is a way of estimating the foundation translation frequency. Because the peak amplification of position $\mathrm{i}$ in mode $\mathrm{j}$ of a lightly damped building is given by $\mathrm{L}_{\mathrm{ij}} / 2 \xi_{\mathrm{j}}$, the same amplification can be achieved for different combinations of EMPF and damping that have the same value of this ratio, i.e., there is an interaction effect in the estimation of these two parameters [10]. The reason for attempting to match both the top floor and the second floor records using the same modal frequencies and damping ratios is to reduce the interaction between the estimates of the damping ratio and the EMPF [7,10].

For the 1993 records, an attempt was made to estimate modal parameters separately in various time windows because of the apparently nonlinear nature of the building's response in the stronger earthquake. Because the building's responses appeared to be dominated by the first two modes, parameters for the first two modes only were estimated.

Although all accelerographs triggered simultaneously in each earthquake, records were digitized independently and no systematic method for record alignment was applied during digitization. Consequently time shifts were necessary to realign the records in the systems identification procedure.

\section{ANALYSIS OF HORIZONTAL RESPONSES}

Parameters for the first two modes of the building in the S46E direction and N44E direction were estimated using the ground floor records and the carpark site records as excitation alternatively and were presented by Zhao et al. [11]. Using the ground floor records as excitation, the modal parameters estimated correspond to those of the structure with a rocking foundation rather than those of a fixed-base structure as commonly used in practical design analysis. Translation of the basement relative to the free field is not accounted for. Using the carpark site record as excitation, the modal parameters of the full soil-structure system are identified, i.e., the basement translation and rocking response are accounted for. In order to estimate the fixed-base modal parameters, more detailed physical modelling of the building and foundation system has to be carried out. Because the building dimension is much larger in the S46E direction than in the N44E direction and the building is not high relative to its dimension in the S46E direction, the foundation rocking response in the S46E direction should be negligible, and the modal parameters estimated in the S46E direction using the ground floor record as excitation should be close to the fixed-base modal parameters in this direction, provided also that the deformation of the concrete mat foundation is small. 
TABLE III: Fundamental Modal Parameters Estimated from the 1993

Records (Time Window 0-40s, Frequency Band 0.4-5 Hz)

\begin{tabular}{|c|c|c|c|c|c|c|}
\hline \multicolumn{3}{|c|}{ Ground floor Input } & \multicolumn{4}{|c|}{ Free-field input } \\
\hline $\begin{array}{l}\bar{\omega}_{\mathrm{h}} / 2 \pi \\
(\mathrm{Hz})\end{array}$ & $\begin{array}{l}\bar{\xi}_{\mathrm{h}} \\
(\%)\end{array}$ & $\overline{\mathrm{L}}_{\mathrm{h}}$ & $\begin{array}{l}\omega_{N} / 2 \pi \\
(\mathrm{Hz})\end{array}$ & $\begin{array}{l}\xi_{N} \\
(\%)\end{array}$ & $\mathrm{L}_{\mathrm{N}}$ & $\mathrm{L}_{\mathrm{b}}$ \\
\hline \multicolumn{7}{|c|}{ N44E Direction } \\
\hline 0.97 & 5.97 & 1.07 & 0.93 & 5.28 & 1.01 & 0.11 \\
\hline \multicolumn{3}{|c|}{ Error $\mathrm{J}=0.15^{*}$} & \multicolumn{4}{|c|}{$\mathbf{J}=0.21$} \\
\hline \multicolumn{7}{|c|}{ S46E Direction } \\
\hline 1.04 & 6.32 & 1.29 & 1.00 & 5.36 & 1.04 & 0.10 \\
\hline \multicolumn{3}{|l|}{$\mathrm{J}=0.08$} & \multicolumn{4}{|c|}{$\mathrm{J}=0.37$} \\
\hline
\end{tabular}

See note in Table II

The fundamental modal parameters estimated from the horizontal responses of the Gisborne Post Office building from the 1982 earthquake are given in Table II where the EMPFs $L_{N}$ and $\bar{L}_{h}$ are for the top floor and $\mathrm{L}_{\mathrm{h}}$ is for the ground floor when using the carpark site records as the excitation. The fundamental modal parameters estimated for the 1993 earthquake are shown in Table III. The modal parameters presented in Tables II and III are slightly different from those reported previously [11] for the case of using carpark site records as excitation because of (a) using ground floor records as responses of the model and (b) accounting approximately for kinematic interactions. Details of the method for accounting for kinematic interaction will be presented elsewhere.

Comparisons of Fourier spectra for the recorded responses of the top floor to those of the model responses using the alternative excitations are shown in Figure 3 for the N44E component of the 1993 records. The model response matches the recorded one very well for the first mode (around $0.9 \mathrm{~Hz}$ ) using either excitation. For the second mode (around 3.5-4.0 Hz), the match is improved using the ground floor record as excitation with respect to that using the carpark site record as excitation.

Comparisons of the acceleration histories for the recorded top floor response and the model response, obtained by using the ground floor record as excitation, can be found in reference [11]. For the 1993 records, the model response was larger than the recorded response in the first half of the records, but smaller in the second half. This indicated that a time-invariant model was not adequate to model even moderately nonlinear responses over a long length of record.

The results are less satisfactory for the response obtained by using the carpark site records as excitation than for the response obtained by using the ground floor record as excitation, as in the case shown by McVerry [8] for a Wellington building. The coupling terms of the foundation dynamic stiffness matrix were not accounted for in the model.

\section{ESTIMATING STRUCTURAL MODAL PARAMETERS}

The Gisborne Post Office building can be modelled by a chain model as shown in Figure 4 where $m_{i}$ is the lumped mass at the ith floor level, and $\mathrm{K}_{\mathrm{uu}}, \mathrm{K}_{\mathrm{rT}}, \mathrm{C}_{\mathrm{uu}}$ and $\mathrm{C}_{\mathrm{r}}$ are the coefficients for the translational and rocking springs and dampers.

Two sets of fundamental natural frequencies and damping ratios are of importance: $\omega_{N}$ and $\xi_{N}$ which are, respectively, the fundamental mode frequency [6] and the damping ratio of the soil-structure system with base rocking and translation, and $\bar{\omega}_{\mathrm{h}}$ and $\bar{\xi}_{h}$, which are, respectively, the fundamental mode frequency and the damping ratio of the soil-structure system fixed at its base in the translational direction with rocking allowed. The relationships between these frequencies and damping ratios and those of the structure and soil-foundation system are given in Equations (6) and (7) in Appendix 1. The relationship of EMPFs $\mathrm{L}_{\mathrm{N}}$ of the soil-structure system with base rocking and translation, $\overline{\mathrm{L}}_{h}$ of the soil-structure system with base rocking only and $\mathrm{L}_{\mathrm{s}}$ of the fixed-base case is given in Equations (8) and (9) in Appendix 1

Using Equation (9b) it can be shown that for both components, $\mathrm{L}_{\mathrm{N}}$ should be very close to $\overline{\mathrm{L}}_{\mathrm{h}}$. The smaller values for $\mathrm{L}_{\mathrm{N}}$ are likely to be caused by the interaction of the estimated values between the EMPF and the damping ratios. For the N44E component, taking $\mathrm{L}_{\mathrm{N}}=1.2$ and scaling the estimated parameters by the ratio of assumed value of 1.2 for $\mathrm{L}_{\mathrm{V}}$ and the estimated value for $\mathrm{L}_{\mathrm{N}}$, the corrected value would be $6.8 \%$ for damping ratio $\xi_{\mathrm{N}}$ and 0.05 for $\mathrm{L}_{\mathrm{b}}$ (assuming that the building base translation is very close to that recorded at the ground floor) 


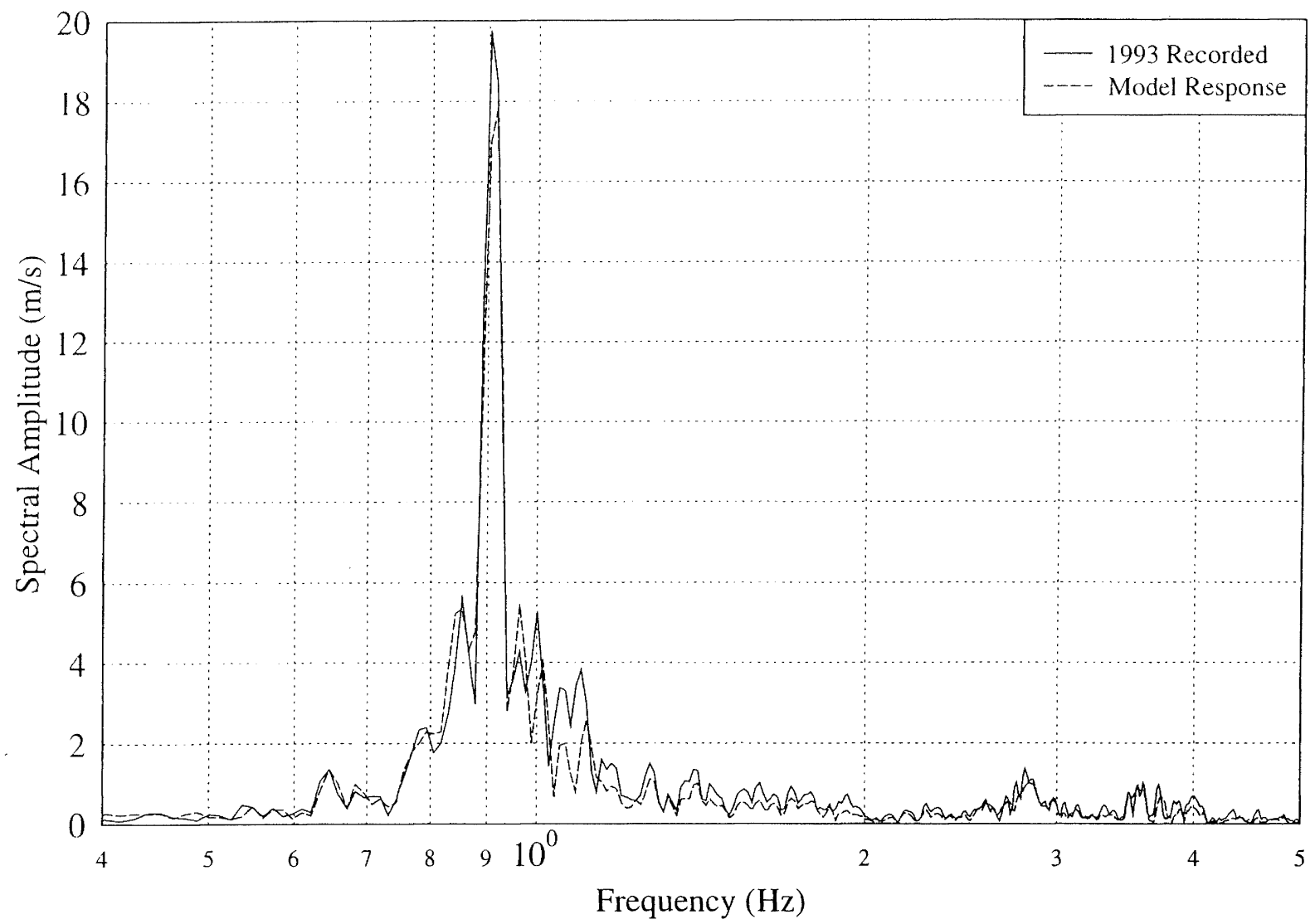

(a). Ground floor record used as excitation

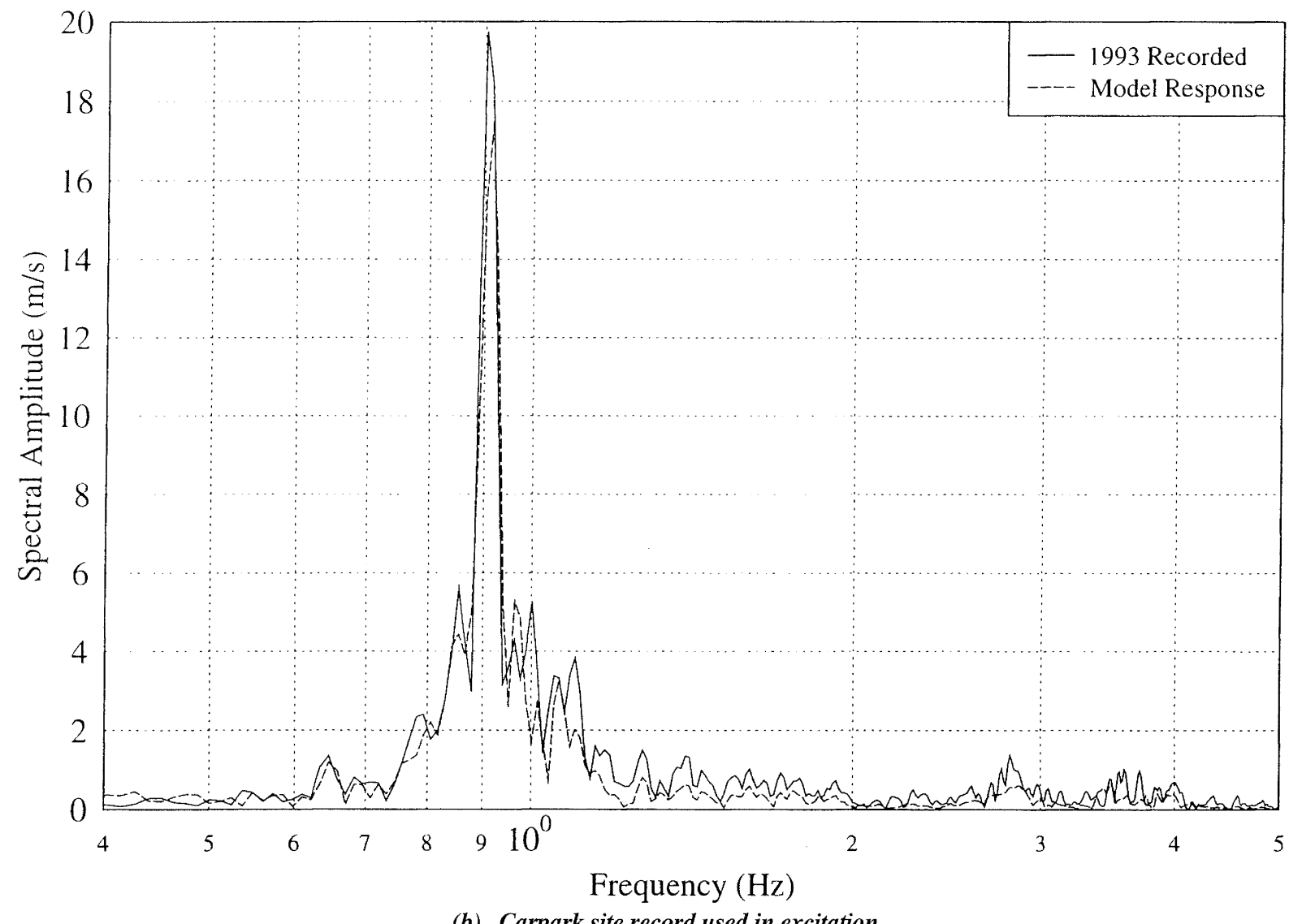

FIGURE 3 Comparison of Fourier spectra for top floor records with those of 2-mode model response for the N44E component. Note some improvement of match using the ground floor record as excitation with respect to using the carpark site record as excitation. 


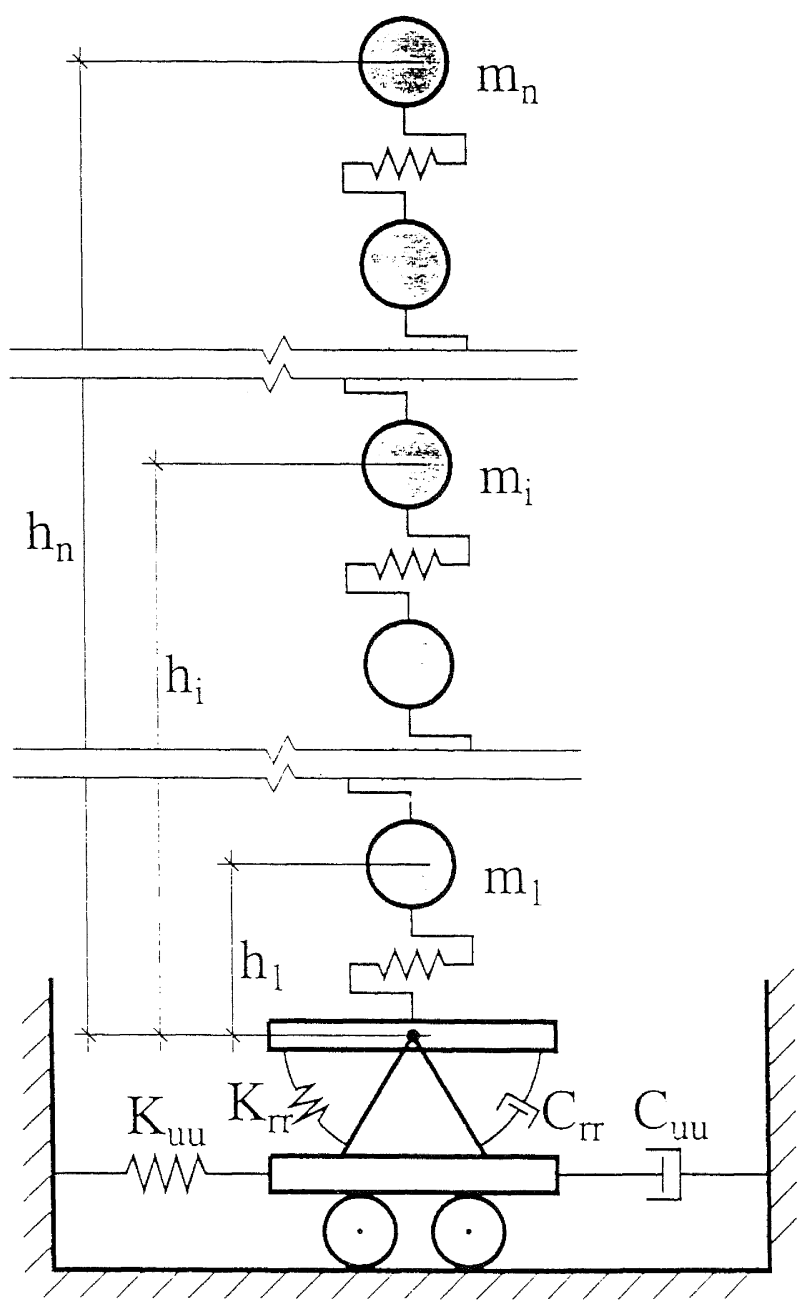

Figure 4. A soil-structure model used for deriving the relationships of various frequencies, damping ratios and EMPFs. The height of floor level $i$ is denoted by $h_{i}$ and the lumped mass by $m_{i}$. The foundation spring and damper coefficients are denoted by $K_{u v}, K_{m}, C_{u w}$ and $C_{r r}$ respectively. This model can also be used for Gisborne Post Office building if the floor of building is assumed to be rigid in its own plane with a lumped mass only.
Foundation translation frequency $\omega_{h} / 2 \pi$ can be estimated either from $\omega_{N}$ and ${ }_{h}$ (Equation $(6 a)$, which gives $5.7 \mathrm{~Hz}$, or from $\mathrm{L}_{\mathrm{h}}$, which gives $4.0 \mathrm{~Hz}$ (Equation (10)). Both values possibly contain errors and they should be taken as a likely range for $\omega_{n}$. Damping ratio $\xi_{\mathrm{h}}$ can be estimated from Equation (6b) and is likely larger than $35 \%$ though its contribution to the over all damping is less than $3 \%$. For the S46E component, the estimated value of $\bar{\omega}_{\mathrm{h}} / 2 \pi$ is 5.2 by using $\omega_{\mathrm{N}}$ and $\bar{\omega}_{\mathrm{h}}$ and $6.5 \mathrm{~Hz}$ by using $\mathrm{L}_{\mathrm{h}}$. These values seem to be too large because the translation stiffness coefficients of two horizontal directions for a rectangular foundation should have similar values. Examination of records showed that the signal to processing noise ratio is only about 2 for the ground floor record in the S46E direction at the frequencies about $\bar{\omega}_{\mathrm{h}}$ and the low signal-to-noise ratio possibly produced relatively large errors in estimating both $\bar{\omega}_{\mathrm{h}}$ and $\mathbf{L}_{\mathrm{h}}$ for this component.

Because of larger amplitudes of the ground motions of the 1993 earthquake than those of the 1982 earthquake, the modal frequencies are about $30 \%$ less than the corresponding ones in Table II. indicating nonlinear responses developed in both the structure and the soils. All EMPFs except for that of the S46E component using ground floor records as the excitation are close to 1.0. The small values for EMPFs are partially caused by the interaction of the estimated values of EMPFs and damping ratios and partially by nonlinear responses (EMPF is no longer constant for a nonlinear system). If we assume that the change of EMPF due to nonlinear response is small, the EMPF of the elastic system can still be used. The corrected values would be $6.7 \%$ for $\bar{\xi}_{\mathrm{h}}$. $6.3 \%$ for $\xi_{\mathrm{N}}$ and 0.13 for $\mathrm{L}_{\mathrm{b}}$ for the N44E component. For the S46E component the corrected values would be $6.6 \%$ for $\xi_{N}$ and 0.12 for $L_{h}$. The foundation translation frequency $\omega_{h} / 2 \pi$ is $2.4 \mathrm{~Hz}$ by using $\mathrm{L}_{\mathrm{b}}$ and $3.3 \mathrm{~Hz}$ by using $\omega_{\mathrm{N}}$ and $\bar{\omega}_{\mathrm{h}}$ (Equation (6)) for the N44E component, and is $2.9 \mathrm{~Hz}$ and $3.6 \mathrm{~Hz}$ for the S46E component. Using the values estimated for $\omega_{\mathrm{h}}$, the damping ratio of foundation translation $\xi_{\mathrm{h}}$ is found to be only about $1-2 \%$ in the N44E direction and $7-11 \%$ in the S46E direction. The smaller damping ratio $\xi_{\mathrm{h}}$ estimated from the 1993 records than that from the 1982 records is likely to be caused by the cut-off frequency, i.e., the fundamental frequency of the soil layer below which radiation damping does not exist if the soil layers are on a rigid bedrock and below which the radiation damping is very small if the soil layers are on a flexible half space (much stiffer than the soil layers) [6]. The site fundamental frequency is reduced from $0.9-1.0 \mathrm{~Hz}$ in the 1982 earthquake to $0.8-0.9 \mathrm{~Hz}$ in the 1993 earthquake indicated by Nakamura's method [12]. In the 1982 earthquake, the fundamental modal frequencies of the soilstructure system in the N44E and S46E directions are higher than the site fundamental modal frequency and the radiation damping ratio is relatively large. In the 1993 earthquake, the fundamental modal frequency of the soil-structure system in the N44E direction is probably very close to or smaller than that of the site and therefore the radiation damping ratio is very small. To verify this aspect, the spring and the damping coefficients of a 2-D foundation-soil model used by Zhao [13,14] for the Gisborne Post Office building are shown in Figure 5 and the damping coefficient for horizontal translational motion is indeed very small at $0.9 \mathrm{~Hz}$ and increases sharply at the frequency range of $0.9-1.5 \mathrm{~Hz}$. 
Because all instruments in the building are near the centre of each floor and rocking motions cannot be detected from any record, the foundation rocking frequency cannot be estimated from the records and therefore the building fixed-base modal frequency cannot be estimated directly from the records either. However, the results from a 2-D numerical modelling of the foundation in the N44E direction (Figure 5(a)) show that the normalized spring coefficient for the rocking motion is 1.8-2.2 times that of the horizontal translation motion in the frequency range of $0.8-1.2 \mathrm{~Hz}$ and the ratio of rocking spring coefficient to horizontal one from the results of Wolf [6] (Figures 7.16a and 7.50a) has a similar value at the fundamental modal frequency of the site. If the ratio can be approximately taken as 2 then it can be shown that

$$
\omega_{\mathrm{r}}=\omega_{\mathrm{h}} \frac{\mathrm{b}}{\mathrm{h}_{\mathrm{e}}} \sqrt{2}
$$

where $b$ is the half width of the foundation in the N44E direction. Taking $h_{\mathrm{e}}=17.0 \mathrm{~m} \mathrm{(2/3}$ of the building height) and $\mathrm{b}=8.25 \mathrm{~m}$, $\omega_{1} \approx 0.7 \omega_{1}$. A possible range for $\omega_{1} / 2 \pi$ is $2.8-4.0 \mathrm{~Hz}$ in the 1982 earthquake and $1.7-2.3 \mathrm{~Hz}$ in the 1993 earthquake for the N44E direction. A possible range for the fixed-base modal frequency is then 1.3-1.4 Hz in the 1982 earthquake and 1.1-1.2 Hz in the 1993 earthquake with a reduction about $10-20 \%$ between the two events, possibly due to nonlinear effects.

Because the foundation has a much larger dimension in the S46E direction than that in the N44E direction, it is expected that the stiffness coefficient for rocking motions in the S46E direction is much larger than that of the N44E direction. The foundation rocking frequency $\omega_{\mathrm{t}}$ in the $\mathrm{S} 46 \mathrm{E}$ direction is expected to be at least twice that for the N44E direction using the expression given by Gazetas et al. [15] (assuming that the ratio of the rocking stiffness coefficients for the two horizontal direction is a function of the foundation geometry only and the frequency dependence of the ratio can be neglected). The estimated frequency $\bar{\omega}_{\mathrm{h}}$ is, therefore, likely to be very close to that of the fixed-base modal frequency $\omega_{s}$ for both earthquakes. The contribution of radiation damping from base rocking in this direction is also likely to be very small and therefore the damping ratio $\bar{\xi}_{\text {h }}$ estimated would be very close to the fixed-base damping ratio $\xi_{\mathrm{s}}$ of about $3 \%$ in the 1982 earthquake and about $6 \%$ in the 1993 earthquake. It is interesting to note that the damping ratio $\bar{\xi}_{\mathrm{h}}$ estimated for the $\mathrm{N} 44 \mathrm{E}$ direction has a similar value to that of the S46E direction, although the contribution to $\bar{\xi}_{\mathrm{h}}$ from foundation rocking radiation damping is expected to be larger in the N44E direction than that in the S46E direction. The similar values for damping ratio $\bar{\xi}_{\mathrm{h}}$ in the two horizontal directions are possibly because $\xi_{\mathrm{r}}$ is small, about $5-10 \%$ indicated by the numerical modelling, and because the fixed-base damping and the radiation damping in the rocking direction both contribute only partially to the system total damping ratio $\bar{\xi}_{\mathrm{h}}$. The radiation damping in the rocking direction does not increase the soil-structure system damping significantly for the Gisborne Post Office building in both earthquakes but the building deformation relative to the base in the N44E direction is much less than that without soil-structure interaction because of the modal frequency decrease and damping increase.

The possible ranges of modal frequencies estimated from the records are given in Table IV for the Gisborne Post Office building.

To further verify the nonlinear response of the building in the 1993 earthquake, the records were separated into different segments according to the acceleration amplitude. For each segment, a time-invariant model was derived. Each segment was treated as independent, with possibly different estimates of the modal parameters, and displacement and velocity continuities were not enforced between the segments. In this way, the mean square error was greatly reduced. For example, the N44E component of the top floor and the ground floor records were divided into segments varying from $0-5 \mathrm{~s}, 5-16 \mathrm{~s}, 16-22 \mathrm{~s}, 22-32 \mathrm{~s}$ and $32-40 \mathrm{~s}$ with an average mean square error of 0.03 . The first mode frequency varied from $1.09 \mathrm{~Hz}$ in the small amplitude motion to $0.91 \mathrm{~Hz}$ in the large amplitude and long period motion. The damping ratio generally increased with the decrease of modal frequency.

Similar analyses were also carried out for the second floor and carpark site records obtained from the 1985 earthquake. The first mode frequency was $1.1 \mathrm{~Hz}$ for the $\mathrm{S} 46 \mathrm{E}$ direction and $1.0 \mathrm{~Hz}$ for the N44E direction. These results indicate that nonlinear building response was also developed in the 1985 earthquake but to a slightly lesser extent than in 1993. Comparison of the model response and the recorded response of the second floor can be found in reference [11].

\section{ANALYSIS OF VERTICAL RESPONSES}

The vertical responses of the Gisborne Post Office building have been analyzed by Zhao [13] and the main results are summarized here.

The vertical peak accelerations obtained in the 1982 and 1993 earthquakes are given in Table I. It can be seen that the building slightly amplified the peak accelerations in the 1982 earthquake. In the 1993 earthquake, the peak acceleration of the ground floor record was reduced by about $30 \%$ compared with that of the carpark record but the peak accelerations of the second floor and the top floor records were considerably amplified. Probable reasons for deamplification of the peak acceleration at the ground floor and amplification on the other floors are that soil-structure interaction was significant, and that the ground shaking had relatively strong amplitudes in the high-frequency range around $10 \mathrm{~Hz}$ in the 1993 earthquake, corresponding to the frequency of the first fixed-base vertical mode of the building.

Using the 1993 ground floor record as excitation and the top floor record as the response, the first vertical fixed-base mode frequency $\omega_{s} / 2 \pi=10.3 \mathrm{~Hz}$ was estimated. Compared with the first fixed-base vertical mode frequency in the 1982 earthquake (12.3 $\mathrm{Hz}$ ), the reduction of the first fixed-base vertical mode frequency is about $20 \%$ presumably because nonlinear response occurred in the structure during the 1993 earthquake. The reduction is consistent with the similar amount of modal frequency reduction estimated for the horizontal responses. The damping ratio of $2.3 \%$ estimated is considerably smaller than that 


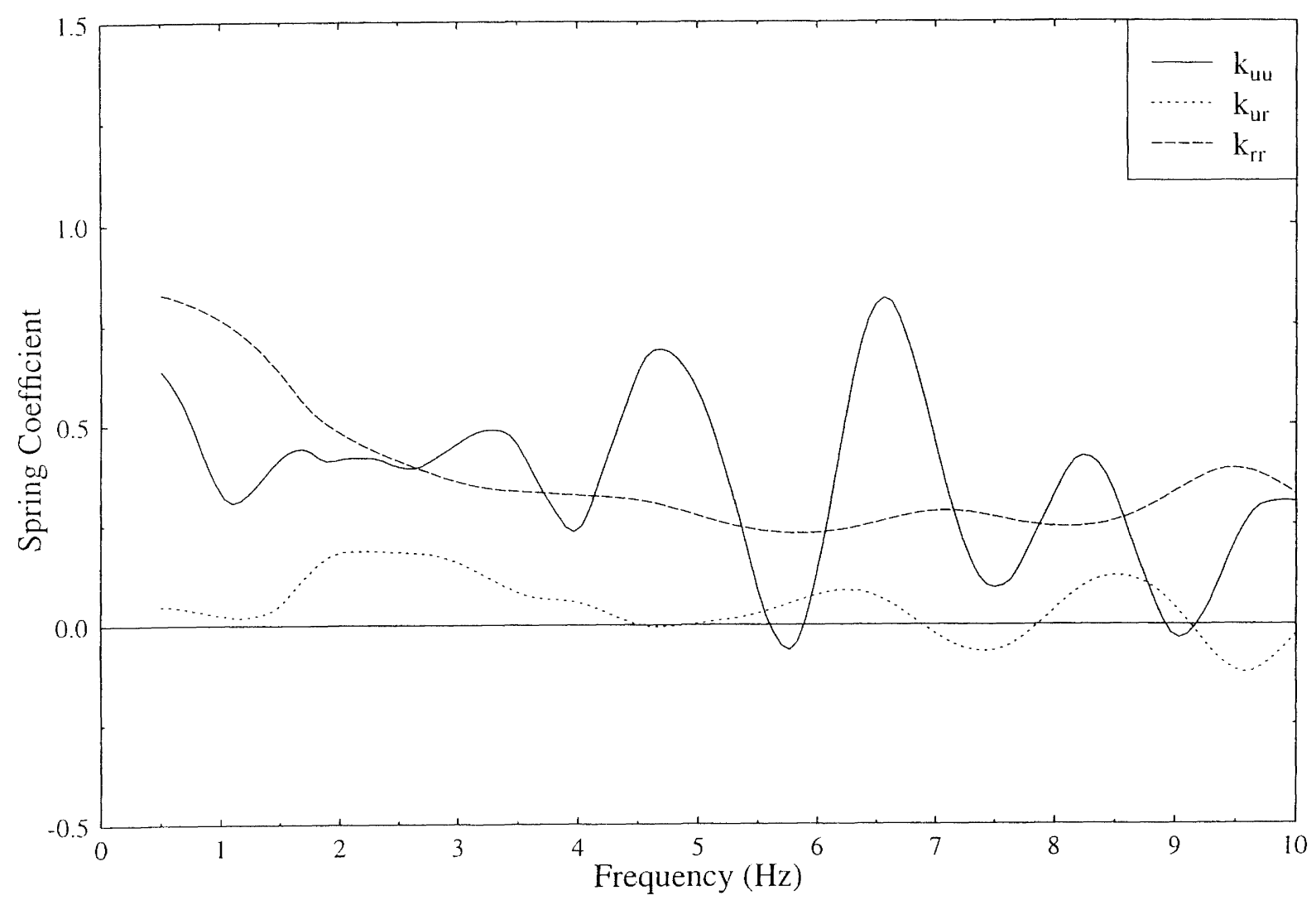

(a). Spring coefficients

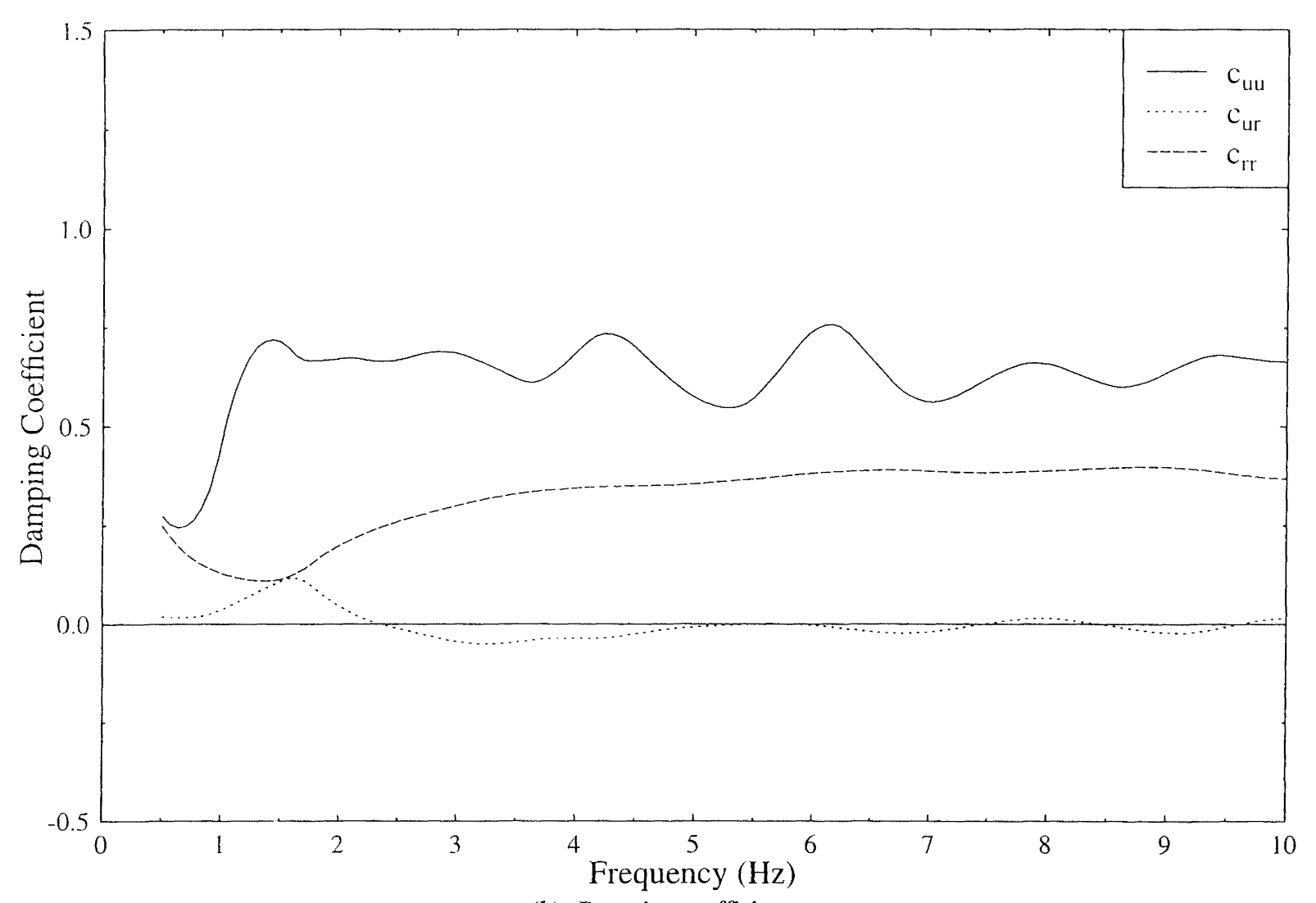

FIGURE 5

(b). Damping coefficients

The spring and damping coefficients for the foundation of the Gisborne Post Office building in the N44E direction using a numerical method. The coefficients have been normalised using a standard procedure for 2-D foundations (see Zhao et al [16]). 
estimated for the horizontal motion of the structure using the ground floor records as excitation (Table III). Part of the reason is that the damping ratio estimated for the horizontal response contains the contribution from the base rocking damping.

The modal parameters of the soil-structure system were estimated by using the 1993 carpark record as excitation and both the top floor and second floor records as the responses $[13,14]$. The first vertical mode frequency of $1.8 \mathrm{~Hz}$ was estimated for the soilstructure system and the first vertical mode damping ratio of $17 \%$ was also estimated. The damping ratio is likely to be greatly under-estimated [13] because of interaction between the estimates of the damping ratio and EMPF, and vertical radiation damping ratios as high as $41 \%$ have been calculated in the literature [15]. The soil-structure system damping ratio is almost entirely contributed by the base vertical translation radiation damping because the fixed-base modal frequency is much larger than the foundation vertical translation frequency. Note that the first vertical modal frequency for the soil-structure system in the 1982 earthquake could not be reliably estimated because of the small amplitudes of motions and very high damping.

\section{SUMMARY \& CONCLUSIONS}

It was found that the average fundamental frequency of the Gisborne Post Office estimated from the 1993 earthquake records decreased about $30 \%$ compared with those estimated from the 1982 earthquake records in both the N44E and S46E directions. In the 1993 earthquake, the fundamental mode damping ratios estimated using the ground floor records as the excitation increased from less than $4 \%$ in the 1982 earthquake to about $6 \%$ for both components, probably because the nonlinear response developed in the structure and soils. When using the carpark records as the excitation, the damping ratios of the first mode in the N44E direction decreased slightly in the 1993 earthquake compared with those in the 1982 earthquake. A possible explanation for the damping ratio reduction in the stronger 1993 ground shaking is that the first modal frequency of the soilstructure system was reduced from above the cutoff frequency of the site in the 1982 event to close to or below the cutoff frequency in the 1993 event, and therefore the contribution from radiation damping in the 1993 event is much less than that in the 1982 event. This explanation is confirmed by the modelling of the foundation-soil system using a numerical method [16]. The implication for the design and analysis of a similar building is that radiation damping cannot be accounted for when the first modal frequency of a soil-structure system is close to the fundamental modal frequency of the soil site.

The modelling was used to estimate the foundation rocking frequency so that the fixed-base modal frequency could be estimated. The fixed-base fundamental modal frequencies of the building were found to be reduced by $10-20 \%$ in the 1993 earthquake compared to those of the 1982 earthquake, presumably due to nonlinear responses developed in the building in the 1993 event. The foundation soil stiffness in both translation and rocking directions was likely to have been reduced by 30 $40 \%$ in the 1993 event. Because the radiation damping decreased in the N44E direction in the 1993 event compared to that in the 1982 event, the increase of damping in the 1993 event is probably mainly due to the increase in fixed-base modal damping in this direction.
When the horizontal components of the 1993 records were separated into a number of segments according to the amplitudes of acceleration responses and a time-invariant model was used for each segment, the average first mode frequency obtained from each segment of the 1993 earthquake records decreased from about $1.1 \mathrm{~Hz}$ in the portion of records with small response amplitudes to about $0.9 \mathrm{~Hz}$ for the portion of records with large response amplitudes in the N44E direction. Similar fundamental frequency changes with time were also found in the S46E direction. The average modal damping ratios were found to increase with the increase of the response amplitudes. These results confirm that nonlinear responses occurred in the 1993 earthquake.

The analysis of vertical responses showed that the fixed-base fundamental modal frequency in the vertical direction also decreased by a similar proportion to that in the horizontal direction in the 1993 earthquake compared to that in the 1982 earthquake.

Soil-structure interaction effect is reasonably significant. Because of damping increase of about $3 \%$ and a small amount of modal frequency decrease due to foundation-soil flexibility, the first fixed-base modal response of the N44E component in the 1982 earthquake was likely to be about $50-60 \%$ of the first modal response of soil-structure system as recorded. In the 1993 earthquake, the fixed-base modal response in the N44E direction was likely to be about $70 \%$ of the first modal response of the soilstructure system because of about $15 \%$ modal frequency reduction due to foundation soil flexibility and a small contribution from radiation damping in the rocking direction. For the vertical response, soil-structure interaction is also very significant. It has been reported by Zhao [13] that the peak acceleration of the top floor would have been $0.43 \mathrm{~g}$ rather than $0.18 \mathrm{~g}$ recorded in the 1993 earthquake if building had been located on a rock site and subjected to the same ground motion.

Although the building exhibited considerably reduced structural stiffness and foundation compliance during its response to the 1993 earthquake neither structural nor foundation damage occurred.

Table IV: $\quad$ Possible ranges of modal parameters estimated from earthquake records for Gisborne Post Office building.

\begin{tabular}{||c|c|c|c|c||}
\hline \multirow{2}{*}{} & $\omega_{s} / 2 \pi(\mathrm{Hz})$ & $\begin{array}{c}\omega_{\mathrm{h}} / 2 \pi \\
(\mathrm{Hz})\end{array}$ & $\begin{array}{c}\omega_{\mathrm{h}} / 2 \pi \\
(\mathrm{Hz})\end{array}$ & $\xi_{\mathrm{h}}(\%)$ \\
\cline { 2 - 5 } & \multicolumn{4}{|c||}{1982} \\
\hline $\mathrm{N} 44 \mathrm{E}$ & $1.35-1.4$ & $2.8-4.0$ & $4.0-5.7^{*}$ & $>35$ \\
\hline $\mathrm{S} 46 \mathrm{E}$ & $1.32-1.4$ & $>5.6$ & $5.2-6.5^{*}$ & $8-12$ \\
\hline & \multicolumn{4}{|c||}{1993} \\
\hline $\mathrm{N} 44 \mathrm{E}$ & $1.1-1.2$ & $1.7-2.3$ & $2.4-3.3$ & $1-2$ \\
\hline $\mathrm{S} 46 \mathrm{E}$ & $1.04-1.1$ & $>3.4$ & $2.9-3.6$ & $7-11$ \\
\hline
\end{tabular}

With possibly large uncertainties. 


\section{APPENDIX 1}

For a building with a massless and zero inertia rigid foundation and a lumped mass $m_{i}$ at each floor level, as shown in Figure 4, resting on translational and rocking springs and dampers with coefficients $\mathrm{K}_{\mathrm{uu}}, \mathrm{K}_{\mathrm{rr}}, \mathrm{C}_{\mathrm{uu}}$ and $\mathrm{C}_{\mathrm{rr}}$, frequencies for foundation translation and rocking are defined by

$\omega_{\mathrm{h}}=\sqrt{\frac{\mathrm{K}_{\mathrm{uu}}}{\mathrm{M}_{\mathrm{e}}}}, \quad \omega_{\mathrm{r}}=\sqrt{\frac{\mathrm{K}_{\mathrm{rr}}}{\mathrm{M}_{\mathrm{e}} \mathrm{h}_{\mathrm{e}}^{2}}}$

$(4 a, b)$

where $M_{e}$ is the equivalent modal mass and $h_{e}$ is the equivalent height [6]. Radiation damping can be replaced by the equivalent linear hysteretic damping ratios defined by (from Equations (3.40) and (3.42) in Wolf [6])

$\xi_{\mathrm{h}}=\frac{\omega \mathrm{C}_{\mathrm{uu}}}{2 \mathrm{~K}_{\mathrm{uu}}}+\xi_{\mathrm{g}}, \quad \xi_{\mathrm{r}}=\frac{\omega \mathrm{C}_{\mathrm{rr}}}{2 \mathrm{~K}_{\mathrm{rr}}}+\xi_{\mathrm{g}}$

$(5 \mathbf{a}, \mathbf{b})$

where $\xi_{\mathrm{g}}$ is the material damping ratio of the surrounding soil and $\omega$ is the circular frequency of excitation.

The first modal frequency $\omega_{N}$ and damping ratio $\xi_{N}$ for the soilstructure system using free-field motion as the excitation can be written as [6]

$$
\begin{aligned}
\frac{1}{\omega_{\mathrm{N}}^{2}} & =\frac{1}{\omega_{\mathrm{s}}^{2}}+\frac{1}{\omega_{\mathrm{h}}^{2}}+\frac{1}{\omega_{\mathrm{r}}^{2}}, \\
\xi_{\mathrm{N}} & =\xi_{\mathrm{s}} \frac{\omega_{\mathrm{N}}^{2}}{\omega_{\mathrm{s}}^{2}}+\xi_{\mathrm{h}} \frac{\omega_{\mathrm{N}}^{2}}{\omega_{\mathrm{h}}^{2}}+\xi_{\mathrm{r}} \frac{\omega_{\mathrm{N}}^{2}}{\omega_{\mathrm{r}}^{2}}
\end{aligned}
$$

The first modal frequency $\bar{\omega}_{\mathrm{h}}$ and damping ratio $\bar{\xi}_{\mathrm{h}}$ for the soilstructure system using base motion as the excitation can be written as [7]

$\frac{1}{\bar{\omega}_{\mathrm{h}}^{2}}=\frac{1}{\omega_{\mathrm{s}}^{2}}+\frac{1}{\omega_{\mathrm{r}}^{2}}, \quad \bar{\xi}_{\mathrm{h}}=\xi_{\mathrm{s}} \frac{\bar{\omega}_{\mathrm{h}}^{2}}{\omega_{\mathrm{s}}^{2}}+\xi_{\mathrm{r}} \frac{\bar{\omega}_{\mathrm{h}}^{2}}{\omega_{\mathrm{r}}^{2}}$

$(7 \mathbf{a}, \mathbf{b})$

It can be shown that parameters $\mathrm{L}_{\mathrm{N}}(\mathrm{h})$ and $\overline{\mathrm{L}}_{\mathrm{h}}(\mathrm{h})$, EMPFs of structural motion at an arbitrary height $\mathrm{h}$ for using free-field motion as the excitation and base motion as the excitation respectively, can be approximately calculated from:

where $L_{s}(h)$ is the EMPF for the fixed-base structure.

$$
\begin{gathered}
\frac{\bar{L}_{\mathrm{h}}(\mathrm{h})}{\mathrm{L}_{\mathrm{s}}(\mathrm{h})}=1+\frac{\bar{\omega}_{\mathrm{h}}^{2}}{\omega_{\mathrm{r}}^{2}}\left[\frac{\mathrm{h}}{\mathrm{h}_{\mathrm{e}} \mathrm{L}_{\mathrm{s}}(\mathrm{h})}-1\right], \\
\frac{\mathrm{L}_{\mathrm{N}}(\mathrm{h})}{\overline{\mathrm{L}_{\mathrm{h}}}(\mathrm{h})}=1+\frac{\omega_{\mathrm{N}}^{2}}{\omega_{\mathrm{h}}^{2}}\left[\frac{1}{\overline{\mathrm{L}_{\mathrm{h}}}(\mathrm{h})}-1\right]
\end{gathered}
$$

Alternatively,

$$
\begin{gathered}
\bar{L}_{h}(h)=\frac{h}{h_{\mathrm{e}}}+\frac{\bar{\omega}_{\mathrm{h}}^{2}}{\omega_{\mathrm{s}}^{2}}\left[\frac{\mathrm{h}_{\mathrm{e}} \mathrm{L}_{\mathrm{s}}(\mathrm{h})}{\mathrm{h}}-1\right] \frac{\mathrm{h}}{\mathrm{h}_{\mathrm{e}}} \\
\mathrm{L}_{\mathrm{N}}(\mathrm{h})=1+\frac{\omega_{\mathrm{N}}^{2}}{\bar{\omega}_{\mathrm{h}}^{2}}\left[\overline{\mathrm{L}}_{\mathrm{h}}(\mathrm{h})-1\right]
\end{gathered}
$$

Equations (8a) and (9a) indicate that when $h_{e} L_{s}(h) / h \geq 1.0$, $\overline{\mathrm{L}}_{\mathrm{h}}(\mathrm{h}) \leq \mathrm{L}_{\mathrm{s}}(\mathrm{h})$ and $\overline{\mathrm{L}}_{\mathrm{h}}(\mathrm{h}) \geq \mathrm{h} / \mathrm{h}_{\mathrm{e}}$, and when $\mathrm{h}_{\mathrm{c}} \mathrm{L}_{\mathrm{s}}(\mathrm{h}) / \mathrm{h} \leq 1.0$, $\overline{\mathrm{L}}_{\mathrm{h}}(\mathrm{h}) \geq \mathrm{L}_{\mathrm{s}}(\mathrm{h})$ and $\overline{\mathrm{L}}_{\mathrm{h}}(\mathrm{h}) \leq \mathrm{h} / \mathrm{h}_{\mathrm{e}}$. Equations (8b) and (9b) indicate that when $\overline{\mathrm{L}}_{\mathrm{h}}(\mathrm{h}) \geq 1.0, \mathrm{~L}_{\mathrm{N}}(\mathrm{h}) \leq \overline{\mathrm{L}}_{\mathrm{h}}(\mathrm{h})$ and $\mathrm{L}_{\mathrm{N}}(\mathrm{h}) \geq 1.0$, and when $\overline{\mathrm{L}}_{\mathrm{h}}(\mathrm{h}) \leq 1.0, \mathrm{~L}_{\mathrm{N}}(\mathrm{h}) \geq \overline{\mathrm{L}}_{\mathrm{h}}(\mathrm{h})$ and $\mathrm{L}_{\mathrm{N}} \leq 1.0$.

It can also be shown that the EMPF for the base motion of the soil-structure system when using free-field motion as the excitation can be approximately calculated from

$$
\mathrm{L}_{\mathrm{b}}=\frac{\omega_{\mathrm{N}}^{2}}{\omega_{\mathrm{h}}^{2}}
$$

\section{ACKNOWLEDGEMENTS}

The author wishes to thank Peter Davenport and Jim Cousins for their review of the manuscript. A part of this paper is from a conference paper (reference [11]) and the author appreciates the contribution from Graeme McVerry and Jim Cousins and the constructive suggestions from Bill Stephenson to that paper. The research presented here was supported by the New Zealand Foundation for Research Sciences and Technology (Contract number C05405)

\section{REFERENCES}

1. Cousins, W.J., Hefford, R.T., McVerry, G.H. and Downer, R.M. (1887), Computer analyses of New Zealand earthquake accelerograms 1981-1985, Volume 2, PEL, DSIR, Lower Hutt, New Zealand

2. Cousins, W.J., Perrin, N.D., McVerry, G.H., Hefford, R.T., and Porritt, T.E. (1996), Ground conditions at Strong-motion recording sites in New Zealand, Science Report 96/33, Institute of Geological \& Nuclear Sciences.

3. Barker, P. (1994), A Report on Cone Penetrometer and Seismic Cone Penetrometer Testing at Selected Sites in Lower North Island, Prepared for Dr. G McVerry, Institute of Geological and Nuclear Sciences, April.

4. Cousins, W.J., Porritt, T.E., Hefford, R.T., Baguley, D.E., O'Kane, S.M. and McVerry, G.H. (1994), Computer analyses of New Zealand earthquake accelerograms, Volume 8, The Tikokino, Fiordland, and Ormond Earthquakes of 1993, Institute of Geological \& Nuclear Sciences, Lower Hutt, New Zealand. 
5. Read, S.A.L. and Cousins, W.J. (1994), The Ormond Earthquake of 10 August 1993: an overview of ground damage effects and strong motions, Proceedings of Technical Conference and AGM, New Zealand National Society for Earthquake Engineering, Wairakei, 18-20 March, 166-175.

6. Wolf, J.P. (1985), Dynamic soil-structure interaction, Prentice-hall, Englewood Cliffs, New Jersey.

7. McVerry, G.H. (1980), Structural identification in the frequency domain from earthquake records, Earthquake Engineering and Structural Dynamics, 3, 161-180

8. McVerry, G.H. (1984), Comparison of remote site and basement records as excitation of the Vogel building, Bull. of N.Z. Soc. for Earthquake Eng, 17, 3-14

9. Novak, M. and Hifnawy, L. EL. (1983), Effect of soilstructure interaction on damping of structures, Earthquake Engineering and Structural Dynamics, 11, 595-621.

10. McVerry, G.H. (1979), Frequency domain identification of structural models from earthquake records, Report No. EERL79-02, Earthquake Engineering Research Laboratory, California Institute of Technology, Pasadena, California.

11. Zhao, J.X., McVerry, G.H. and Cousins W.J. (1995), Horizontal responses of Gisborne Post Office building in two earthquakes, Proceedings of Technical Conference of New Zealand National Society for Earthquake Engineering, Rotorua, New Zealand, March, 69-76.

12. Nakamura, Y. (1989), A method for dynamic characteristics estimation of subsurface using microtremor on the ground surface, Quarterly Review of Railway Technical Research Institute, 30, 25-33.

13. Zhao, J.X. (1995), Vertical soil-structure interaction of the Gisborne Post Office building, Proceedings of Pacific Conference on Earthquake Engineering, 3, 227-236.

14. Zhao, J.X. (1976), Effects of frequency dependent foundation-soil compliance on building vertical responses identified from earthquake records, Soil Dynamics and Earthquake Engineering, 16, 273-284.

15. Gazetas, G. (1991), Formulas and charts for impedances of surface and embedded foundations, Journal of Geotechnical Engineering, ASCE, 117, 1363-1381.

16. Zhao, J.X., Carr, A.J. and Moss, P.J. (1997), Calculating the dynamic stiffness matrix of 2-D foundations by discrete wave number indirect boundary element methods, Earthquake Engineering and Structural Dynamics, 26, 115-134. 